\title{
Calidad del Padrón Electoral y elecciones confiables
}

\author{
Quality of voter registration and reliable elections
}

\author{
Carlos Welti Chanes \\ Instituto de Investigaciones Sociales de la Universidad Nacional \\ Autónoma de México, México
}

\begin{abstract}
Resumen
La intención de este artículo es mostrar cómo se ha venido construyendo un Padrón Electoral, para que éste constituya un instrumento básico en la realización de elecciones confiables en México, lo que ha podido ser posible a través de la participación de los actores en esta tarea y que son: ciudadanos, partidos políticos y autoridades que administran los procesos electorales. El texto, hace referencia a los arreglos institucionales concretados en leyes, códigos y reglamentos que tienen este objetivo y que han servido de marco a las actividades de creación y actualización del instrumento registral. Una acción muy importante de evaluación del Padrón lo constituyen las Verificaciones Nacionales Muestrales, a través de las cuales, de manera sistemática, y única en el mundo, desde 1994, se ha estimado la cobertura del Padrón y el estado de actualización de la Lista Nominal observable a nivel nacional, regional o incluso estatal, de tal manera que su conocimiento sirva de base para su mejora permanente. El artículo muestra que la credencial de elector constituye el documento de identidad ciudadana más confiable en México.
\end{abstract}

Palabras clave: Elecciones, padrón electoral, credencial de elector.

\section{Abstract}

The aim of this article is to show how the Voter Registration has been built, so that it constitutes a basic instrument in the realization of reliable elections in Mexico, and to make clear that this has been possible through the participation of the main actors in this task: citizens, political parties and authorities that administer the electoral processes. The text describes the institutional arrangements specified in laws, codes and regulations that have this objective and that have served as a framework for the activities of creation and updating of the voter registration system. A very important instrument of evaluation of the Register is the National Survey of Verification, through which, systematically since 1994, the coverage of the Register and the update of the "Nominal List" have been estimated, at national, regional or even at State level, in such a way so that this knowledge serves as the basis for their permanent improvement. The article shows that the voter identification card constitutes the most reliable citizen identity document in México.

Key words: Elections, voter registration, voter identification card. 


\section{INTRODUCCIÓN}

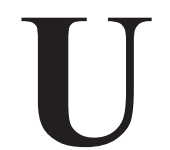

$\mathrm{n}$ instrumento elemental y básico en una organización en la cual sus integrantes eligen a través de una votación a las autoridades que integrarán sus órganos de gobierno, es una lista de las personas que tienen derecho a participar en esa elección. La tarea de construir este instrumento, aparentemente sencilla, adquiere diferentes grados de complejidad según la organización que la requiera y que puede ser, desde un club, una sociedad de estudiantes o profesionistas, los accionistas de una empresa, un sindicato, un partido político o en el extremo, todo un país.

El instrumento referido constituye una lista de personas que se construye a partir de una serie de condiciones que impone el marco normativo que rige su conformación y que incluye: i) quiénes la integraran y qué requisitos deben cumplir para formar parte de ella; ii) cómo serán identificados sus integrantes; iii) cuál será el medio físico en que se mantenga esta lista y iv) quién y cómo se manejará esta lista cada vez que se requiera en un proceso electoral.

La primera condición, el registro inicial, puede generarse automáticamente cuando la persona queda inscrita en el padrón incluso, sin solicitarlo, por ejemplo, cuando habiendo sido registrada, al obtener una cédula de identidad al nacimiento alcanza cierta edad o bien, cuando acumula cierta antigüedad como miembro de una organización; o, por otra parte, cuando solicita expresamente su registro y queda integrada a esta lista si cumple con los requisitos establecidos para ello.

En el caso de una organización como un club, o una asociación de profesionistas, es evidente que el hecho de desear formar parte de ésta y formalizar este deseo,constituye la acción de registrarse; sin embargo, en cierto momento, la persona puede dejar de cumplir los requisitos que hicieron posible no sólo su registro, también el derecho de sufragar en una elección; por ejemplo, porque deja de pagar las cuotas que implica su membresía o se desvía del código de conducta impuesto por la normatividad de la organización. Toda proporción guardada, lo mismo sucede en un país, en el cual un ciudadano que se registró en el Padrón de Electores puede quedar fuera de éste por incumplir los requisitos que se lo permitieron, por ejemplo, al perder su derecho a ejercer el voto porque recibió la condena de un juez por haber cometido un delito. 
En la fecha de una elección, identificar a los integrantes de una organización, cuando desean participar en procesos electorales, si ya están inscritos en un listado de potenciales electores, puede hacerse a través del conocimiento personal que de ellos tienen quienes se encargan de administrar estos procesos, situación sencilla en organizaciones con un reducido número de miembros $\mathrm{o}$, mediante documentos que respaldan su registro. Es obvio que las dimensiones de una organización cuando ésta tiene un elevado número de miembros dificulta la identificación de cada uno de ellos por el conocimiento personal y requiere documentarla.

El medio físico en que se mantendrá el listado de personas es, desde luego, otro aspecto sustantivo del instrumento registral, lo que significa tomar en cuenta el material y el tipo de dispositivo que lo contenga. En la actualidad, se puede suponer que, independientemente de sus dimensiones, todo registro estará contenido en medios magnéticos para ser procesado en una computadora, lo que facilitará su administración y distribución entre las personas encargadas de esta tarea, lo que incluye la verificación de su calidad y su actualización.

Finalmente, el uso de un instrumento de esta naturaleza deberá sujetarse a determinadas reglas cuya aplicación estará a cargo de las personas que la propia organización ha designado para administrarlo y que deben garantizar que se utiliza para los propósitos para los que fue creado.

El proceso descrito de manera muy simple, constituye en la práctica una tarea en extremo compleja en función de las dimensiones y características de la organización de que se trate. En el caso de elecciones en cualquier país democrático, la creación y mantenimiento de un instrumento registral que haga posible que todos los ciudadanos, y sólo los ciudadanos, que tienen el derecho a elegir a sus autoridades puedan hacerlo, es una parte medular de una elección y requiere del concurso de gran cantidad de personas y recursos materiales especializados y el aprovechamiento de la experiencia acumulada en cada uno de los procesos electorales previos.

La calidad del listado de electores es una condición básica para garantizar que una elección es confiable y por tanto, este texto tiene como objetivo hacer un análisis de lo que ha significado la creación en México de un Padrón Electoral de calidad, a través de las acciones en las que participan ciudadanos, partidos políticos y organizaciones electorales encargadas de su administración, para lograr en la actualidad que éste sea un instrumento en el cual la ciudadanía puede confiar.

Un Padrón de calidad significa tener un registro de electores confiable, que cumpla con dos condiciones básicas: i) que sea preciso con respecto 
a la población que en él está representada y ii) que sea válido, al no tener sesgos que excluyan a ciertos grupos de la población de su registro y por tanto, que en este Padrón, se encuentran registrados quienes deben estar y sólo quienes deben estar.

En México, a través de su historia electoral documentada, se puede constatar la diversidad de formas que ha tenido el registro de electores desde hace siglos; sin embargo, en la forma actual como un Padrón Electoral moderno y confiable con un soporte documental que incluye una credencial de elector con fotografía, su existencia es muy reciente.

El análisis de la evolución del Padrón Electoral permite identificar condiciones estructurales y acciones de los actores que lo integran, lo promueven o, lo administran, y que de distintas formas afectan el Padrón y que se enlistan a continuación:

a) Procesos demográficos, como la mortalidad o la migración, que modifican la población de electores.

b) Prácticas individuales relacionadas con hechos como la inscripción de los ciudadanos al propio padrón, la notificación de su cambio de domicilio o la obtención de su credencial de elector y su renovación.

c) Prácticas de las organizaciones como son los partidos políticos que pueden incidir en los comportamientos de los ciudadanos respecto a su registro como electores y la actualización de sus condiciones de residencia.

d) Las acciones de las organizaciones encargadas de documentar la exclusión definitiva o temporal de un ciudadano de la vida civil, ya sea por defunción, lo que corresponde al Registro Civil, o por la pérdida de sus derechos políticos, lo que corresponde al Poder Judicial y finalmente.

e) El Registro Federal de Electores como la organización directamente responsable de la administración del padrón.

\section{Evolución del Padrón Electoral en México}

Al iniciar el año 2018, año en el que se realizaron elecciones presidenciales, el Padrón Electoral lo constituían 89'257,456 ciudadanos, y la Lista Nominal contenía 87'963,104 registros de ciudadanos que una vez empadronados habían recogido su credencial de elector en los módulos del INE. ${ }^{1}$

Para tener una idea de las dimensiones de este instrumento registral, este Padrón equivale a la suma de los Padrones de varios países de América

\footnotetext{
${ }^{1}$ Cifras al 31 de diciembre de 2017.
} 
Latina y sólo el Padrón del Estado de México, con 11.7 millones de ciudadanos, supera en número al de Bolivia o Cuba, por ejemplo. En el extremo opuesto, la entidad con el menor número de registros en el Padrón es Baja California Sur con tan sólo 510 mil personas, pero con una dinámica acelerada de crecimiento.

El incremento de la población de 18 o más años y la cobertura creciente del Padrón, explican su evolución numérica. Sin embargo, la comparación entre esta población a partir de las cifras censales con las dimensiones del Padrón ha generado en años recientes la idea de que este instrumento registral no es confiable, porque supera en forma significativa a la población que podría estar empadronada, es decir, podría suponerse una acción deliberada por "inflar" el Padrón; no obstante, esta situación puede explicarse, por la naturaleza de las fuentes de datos que se comparan. En el caso del censo, la población representa un corte transversal, una fotografía, en la fecha de levantamiento, que además, tiene cierto grado de subregistro, mientras que el Padrón contiene información longitudinal que se acumula con el paso del tiempo y cuyo monto se ve afectado por su desactualización. Veamos con cifras esta situación. En 1960, cuando el Padrón se compara con las cifras censales se observa que la población de 18 o más años, fue de 17.2 millones y el Padrón lo constituyeron alrededor de 10 millones de ciudadanos (Gómez Tagle, 1990). Con estas cifras y en una operación muy simple se puede estimar que la cobertura era apenas de 58 por ciento de la población en edad de votar. Las cifras para 1970 mostraron una población censal en edad ciudadana, de 22.8 millones y el Padrón según las cifras de Gómez Tagle (Gómez Tagle, 1990) alcanzaba 21.6 millones por lo que, la comparación llevaría a estimar que la cobertura del Padrón sería de 95 por ciento, cifra poco creíble, ya que si bien los ciudadanos incrementaron su registro en décadas recientes, la población mostraba poco interés tanto por participar en las elecciones, como por obtener su credencial de elector cuando ésta no constituía un documento de identificación personal como ocurrió años después.

En realidad, en estas décadas, son las problemáticas acumulativas las que se hacen ya evidentes en el crecimiento del número de ciudadanos en el Padrón y son entre otras razones, las que originaron desconfianza en el instrumento registral al suponer que "se inflaba" de manera intencional.

La comparación de los datos del Padrón usado en las elecciones de 1982 y las proyecciones de la población de ciudadanos a partir de las cifras del Censo de 1980, también permitiría estimar que la cobertura sería de alrededor de 95 por ciento. Las cifras a nivel nacional pueden ser plausibles, 
específicamente, porque la cifra de empadronados si bien es alta, no supera las cifras poblacionales; sin embargo, cuando las cifras se desagregan a nivel de las entidades federativas o municipios, resultan situaciones en las que el Padrón supera significativamente el número de ciudadanos censados, pero esto, como ya se mencionó, tiene su origen en la naturaleza de cada fuente, de tal manera que la desactualización del Padrón producto de la migración y la mortalidad incrementa el volumen de registros, ya que se mantiene en el Padrón a emigrantes a otra entidad o a otro municipio, e incluso a otro país, que no actualizaron su lugar de residencia y además permanecen registrados fallecidos que no son dados de baja, porque al Registro Federal de Electores no llegaba con oportunidad (o simplemente no llegaba), la información que justificara su eliminación del instrumento registral.

En 1990, el número de ciudadanos (personas de 18 o más años) según los datos censales alcanzó 43.6 millones de personas y el Padrón al 31 de junio de 199139.2 millones, ${ }^{2}$ por lo que sería posible estimar que, si no hubiera desactualización del Padrón, con la evolución de la población, la cobertura sería de alrededor de 90 por ciento.

Por cierto, en estos años, el empadronamiento se incrementó, porque en la búsqueda de condiciones que lo incentivaran, en 1992 se logró un acuerdo entre el Instituto Federal Electoral (IFE) y la Asociación Mexicana de Bancos para aceptar la credencial de elector como identificación personal, lo que tuvo un efecto positivo sobre el registro. ${ }^{3}$

En el Censo de Población y Vivienda del año 2000, la población en edad de votar alcanzó 56.7 millones de personas y las cifras del padrón

${ }^{2}$ Cifra proveniente de: Memorias del Proceso Electoral Federal de 1991. Instituto Federal Electoral. Tomo II, Vol. 3. Instituto Federal Electoral. 1993.

${ }^{3}$ El hecho de que fuera aceptada la credencial de elector como documento de identificación personal, entre otras cosas, para hacer trámites bancarios, al iniciar la década de los años 90 , efectivamente incentivó en forma significativa el registro en el Padrón, porque en México no existe un documento único de identificación personal como puede ser la "Tarjeta de Identidad" y la "Cédula de Ciudadanía" en países como Colombia. El lector debe saber que el Art. 36 en su fracción I, de la Constitución Polícia de los Estados Unidos Mexicanos establece la obligación de inscribirse en el Registro Nacional de Ciudadanos para obtener el documento que acredite la ciudadanía mexicana y el cual debe ser expedido por la autoridad respectiva; sin embargo, en la práctica hasta ahora esto no se ha cumplido. Aunque la creación del Registro Nacional de Población se hizo con este propósito, es la credencial de elector el documento que identifica a las ciudadanas y ciudadanos de este país.

Por el efecto positivo de esta experiencia, en el año 2010, la Comisión del Registro Federal de Electores, se propuso lograr un acuerdo con la Asociación Mexicana de Bancos para que no se aceptaran las credenciales que ya no estaban vigentes, con el fin de incentivar su renovación. Según se describe en la nota del periódico El Universal del día 20 de diciembre de 2010, titulada ABM renueva convenio para aceptar la credencial del IFE, firmada por José Gerardo Mejía, "en el convenio se consigna que en los casos en que ciudadanos presenten la credencial para votar 03 como medio de identificación al realizar sus trámites, las instituciones de crédito invitarán a los ciudadanos a acudir a los módulos para renovarla". 
para el mes de febrero de ese año representaron 59.8 millones (Ordorica y Flores, 2003), aunque el número de empadronados superaba a la población ciudadana censada, el monto diferencial refleja, por una parte, un incremento del registro influenciado no sólo por el interés de la ciudadanía por participar en los procesos electorales, también por la necesidad de contar con un documento de identificación personal, que con carácter universal hasta la fecha no existe en México y por otra parte, hacía evidente la desactualización del Padrón y reiteraba la necesidad de intensificar las tareas para actualizarlo, ya que el instrumento registral acumulaba miles de personas que habían emigrado a otro país y personas que habían fallecido y que seguían apareciendo en el Padrón. ${ }^{4}$

Para tener una idea cada vez más cercana de lo que ha representado la tarea de construir un Padrón confiable en México, la magnitud de ésta tarea se aprecia si comparamos las cifras de personas de 18 o más años en el Censo de Población y Vivienda de 2010, 71.7 millones, y el Padrón, con los cortes temporales de las fechas más cercanas a la fecha censal, ya sea el 31 de diciembre de 2009, con 79 millones de empadronados o el 31 de diciembre de 2010, con 81.4 millones, las cifras son superiores a la población censada en más de diez por ciento, y está diferencia, independientemente de la sub enumeración censal, se origina en la desactualización del Padrón.

Esta problemática, que se ve reflejada en esta comparación, ha tenido que ser atendida por el Instituto Nacional Electoral y su área operativa representada por el Registro Federal de Electores a través de diversas acciones que se describen en los apartados que siguen y que han sido impulsadas por los partidos políticos y los propios ciudadanos en lo individual o como miembros de organizaciones de la sociedad civil.

\section{Antecedentes institucionales de la mejora del Padrón}

En el ámbito político, los años previos al inicio de la década de los 90, fueron un periodo en el que se discute la Reforma Electoral como respuesta a los cuestionamientos que los partidos políticos de oposición al partido en el gobierno hacían a la confiabilidad de los procesos electorales. En este proceso, un tema recurrente es la crítica al Padrón de electores.

\footnotetext{
${ }^{4}$ El análisis de Ordorica y Flores previamente citado usó como referencia las proyecciones de población elaboradas por el Consejo Nacional de Población (CONAPO), en lugar de las cifras del censo con el argumento de que: "Se utilizan las proyecciones de población, no la información censal, debido a que se supone que las proyecciones ya corrigieron problemas de omisión y los faltantes demográficos provocados por la migración. O sea, las proyecciones presentan una población corregida y supuestamente más cercana a la realidad" (Ordorica y Flores, 2003: 9).
} 
En el análisis realizado por Zúñiga, Borrego e Ibarra (2003), en su evaluación del Padrón Electoral como parte del Comité Técnico formado por la autoridad electoral con este propósito, se presenta un resumen de las ideas expresadas en la Séptima Audiencia Pública sobre la Reforma Electoral, realizada el 15 de marzo de 1989, que es muy ilustrativo del interés por abordar las problemáticas de este instrumento.

Anotan los autores lo que se dijo acerca del Padrón en aquella Audiencia y que se resume en la minuta:

presenta serias deficiencias: ciudadanos incluidos varias veces, ciudadanos empadronados y con credencial para votar que no aparecen en las listas nominales, obstáculos incomprensibles para empadronarse, menores de edad empadronados, sobreempadronamiento en secciones electorales, listas nominales idénticas en varias casillas... El Padrón Electoral es la causa de una parte sustancial de la abstención electoral. El fraude electoral radica en el diseño mismo del Padrón Electoral. Los partidos políticos no tienen la posibilidad de revisar el Padrón; lo único que pueden hacer es levantar un padrón paralelo (Zúñiga, Borrego e Ibarra, 2003: 5).

Con el Código Federal de Instituciones y Procedimientos Electorales (COPIFE) de 1990, se crea el Instituto Federal Electoral y junto con él, se propone la elaboración de un Padrón moderno y confiable.

Por su importancia, se citan a continuación diversas disposiciones del COPIFE relacionadas con la construcción y mantenimiento del Padrón y el papel que se les asigna a los actores: ciudadanos, partidos políticos y autoridades en esta materia.

Este Código establece que: "Para la elección federal de 1991 se elaborará un nuevo Padrón Electoral" (Art. Décimo Transitorio), y que: "Para las elecciones federales a celebrarse a partir de 1994, ... Se expedirá una Nueva Credencial para Votar con fotografía" (Art. Decimoséptimo Transitorio).

El COPIFE, en el Artículo 92 le otorga a la Dirección Ejecutiva del Registro Federal de Electores las siguientes atribuciones:

a) Formar el Catálogo General de Electores.

b) Aplicar, en los términos de artículo 141 de este Código, la técnica censal total en el territorio del país para formar el Catálogo General de Electores.

c) Aplicar la técnica censal en forma parcial en el ámbito territorial que determine la Junta General Ejecutiva.

d) Formar el Padrón Electoral. 
e) Expedir la Credencial para Votar según lo dispuesto en el Título Primero del Libro Cuarto de este Código.

f) Revisar y actualizar anualmente el Padrón Electoral conforme al procedimiento establecido en el Capítulo Tercero del Título Primero del Libro Cuarto de este Código.

g) Establecer con las autoridades federales, estatales y municipales la coordinación necesaria, a fin de obtener la información sobre fallecimientos de los ciudadanos, o sobre pérdida, suspensión u obtención de la ciudadanía. ${ }^{5}$

En este mismo Artículo 92 del COPIFE, queda además definido puntualmente el rol de los partidos políticos en la construcción y mantenimiento del Padrón a través de su participación en las instancias que se crean con este propósito, la Comisión Nacional de Vigilancia y las Comisiones Locales y Distritales de Vigilancia, que constituyen un espacio organizacional especialmente significativo para garantizar su participación en estas tareas.

Por otra parte, el Artículo 139 del COPIFE, hace obligatorio para los ciudadanos inscribirse en el Registro Federal de Electores y "participar en la formación y actualización del Catálogo General de Electores y del Padrón Electoral en los términos de las normas reglamentarias correspondientes".

Con respecto a la técnica censal que, para cumplir con la normatividad, el Registro Federal de Electores debe aplicar para construir el nuevo Padrón, la define el Artículo 141 como "el procedimiento que se realiza mediante entrevista casa por casa, a fin de obtener la información básica de los mexicanos mayores de 18 años", lo que sirve para formar el Catálogo General de Electores y una vez concluido, "la Dirección Ejecutiva del Registro Federal de Electores verificará que en el Catálogo General no existan duplicaciones, a fin de asegurar que cada elector aparezca registrado una sola vez" (COPIFE, Art. 141. 4).

Después de la depuración de este Catálogo, "para la incorporación al Padrón Electoral se requerirá solicitud individual en que consten firma, huella digital y fotografía del ciudadano" (COPIFE, Art. 143. 1). A partir de esta solicitud, el Registro Federal de Electores expide la Credencial para Votar que los ciudadanos deben recoger en los módulos que determine el Instituto Federal Electoral para quedar incluidos en la Lista Nominal de electores.

${ }^{5}$ Código Federal de Instituciones y Procedimientos Electorales. Diario Oficial de la Federación 15 de agosto de 1990. 
Para actualizar el Catálogo General de Electores y el Padrón Electoral, dice la norma: "la Dirección Ejecutiva del Registro Federal de Electores realizará anualmente, a partir del día 1o. de octubre y hasta el 15 de enero siguiente, una campaña intensa para convocar y orientar a la ciudadanía a cumplir con las obligaciones a que se refieren los dos párrafos siguientes:

Durante el periodo de actualización deberán acudir ante las oficinas de la Dirección Ejecutiva del Registro Federal de Electores, en los lugares que ésta determine, para ser incorporados al Catálogo General de Electores, todos aquellos ciudadanos:

a) Que no hubiesen sido incorporados durante la aplicación de la técnica censal total.

b) Que hubiesen alcanzado la ciudadanía con posterioridad a la aplicación de la técnica censal total.

Durante el periodo de actualización también deberán acudir a las oficinas los ciudadanos incorporados en el Catálogo General de Electores y el Padrón Electoral que:

a) No hubieren notificado su cambio de domicilio.

b) Incorporados en el Catálogo General de Electores no estén registrados en el Padrón Electoral.

c) Hubieren extraviado su Credencial para Votar.

d) Suspendidos en sus derechos políticos hubieren sido rehabilitados" (COPIFE, Art. 146).

Asimismo, el Artículo 162, establece que:

1. A fin de mantener permanentemente actualizados el Catálogo General de Electores y el Padrón Electoral, la Dirección Ejecutiva del Registro Federal de Electores recabará de los órganos de las administraciones públicas federal y estatal la información necesaria para registrar todo cambio que lo afecte.

2. Los servidores públicos del Registro Civil deberán informar al Instituto Federal Electoral de los fallecimientos de ciudadanos, dentro de los diez días siguientes a la fecha de expedición del acta respectiva.

3. Los jueces que dicten resoluciones que decreten la suspensión o pérdida de derechos políticos o la declaración de ausencia o presunción de muerte de un ciudadano, deberán notificarlas al Instituto Federal Electoral dentro de los diez días siguientes a la fecha de la respectiva resolución. 
4. La Secretaría de Relaciones Exteriores deberá dar aviso al Instituto Federal Electoral dentro de los diez días siguientes a la fecha en que:

a) Expida o cancele cartas de naturalización.

b) Expida certificados de nacionalidad.

c) Reciba renuncias a la nacionalidad.

5. Las autoridades señaladas en los párrafos anteriores deberán remitir la información respectiva en los formularios que al efecto les sean proporcionados por el Instituto Federal Electoral".

Como puede constatarse, el COPIFE de 1990, establece las bases normativas para crear un Padrón: i) moderno, porque incorpora la tecnología disponible más avanzada en ese momento para su construcción y ii) de calidad y confiable, porque se plantea que tenga una cobertura de carácter universal y actualizada, y para lograrlo, se identifica el rol específico de cada uno de los actores en este proceso.

En la coyuntura a la que se ha hecho referencia, el IFE responde al mandato del COPIFE, y establece el Programa "Padrón Electoral 1991", para construir el instrumento a utilizarse en las elecciones federales del año 1992.

Esta tarea que de manera inicial consistió en visitar todas las viviendas del país para identificar a los ciudadanos residentes en ellas, significó implementar la Técnica Censal Total y sirvió para invitar a todos los ciudadanos a registrarse en el Padrón.

Las acciones descritas y que son poco conocidas por la ciudadanía, fueron la base para iniciar la construcción de un Padrón confiable.

\section{¿Cómo Se INICIA La CONSTRuCCión de un PADRón CONFIAble?}

Es posible afirmar que por su calidad, México tiene uno de los mejores Padrones Electorales del mundo. Esta afirmación valorativa que puede parecer exagerada está sustentada técnicamente. Sin embargo, con toda razón quienes escuchan este juicio de valor sobre el instrumento registral, plantean como exigencia para aceptarlo tener los resultados de un análisis comparativo que involucre a todos los países. Como este análisis comparativo es una tarea que supera los objetivos de este texto al analizar este Padrón, debe matizarse el juicio anterior, diciendo que México tiene un Padrón cada vez de mejor calidad y esto se puede constatar con la información disponible.

El Programa Padrón Electoral 1991, con el cual se construyó el Padrón actual, incluyó antes de iniciar sus actividades la formación de un Grupo de 
Asesores Técnicos de los Partidos Políticos cuya función fue la de "conocer y analizar las diferentes actividades del programa y en su caso, realizar las observaciones pertinentes; asimismo, son (sic) el enlace técnico entre el Registro Nacional de Electores y el Comité Técnico y de Vigilancia del Propio Registro" (IFE, 1993. Tomo II, vol. 2, P. 11). Es decir, no sólo los partidos políticos participaron en este proceso a través de sus representantes; además, por la naturaleza técnica de las actividades fueron apoyados por especialistas en los diversos temas designados por estas mismas organizaciones. Estos temas fueron: Comunicación, Informática, Cartografía, Operativo de campo, Capacitación y Organización; es decir, cubrieron los temas torales en la creación de un registro de esta naturaleza.

Al iniciar la construcción de un nuevo Padrón, la necesidad de garantizar que este proceso se hiciera en las mejores condiciones obligó a que se auditara cada una de las etapas que lo conformaron. Para realizar esta tarea se contrató a dos empresas de reconocido prestigio a nivel internacional: A. C. Nielsen Co. y MacKinsey and Company, Inc. La primera, estuvo dedicada a evaluar el trabajo de campo para estimar por entidad federativa la proporción de viviendas y ciudadanos omitidos al aplicar la técnica censal completa e identificar las causas de esta omisión. La segunda empresa evaluó la elaboración del Catálogo de Electores, el Padrón, la entrega de Credenciales de Elector y la Lista Nominal.

Se reproducen a continuación las conclusiones de esta evaluación, contenidas en el informe respectivo:

El Programa sobrepasó las metas preestablecidas de cobertura, logrando que 85.6 por ciento de la ciudadanía quedara empadronada y que 92.6 por ciento de los empadronados recibieran oportunamente su credencial para votar. La información de los electores, contenida en las credenciales y, por lo tanto, en las listas nominales, es correcta en 97 por ciento de los casos. En tres por ciento restante, los errores se distribuyen aleatoriamente entre datos de domicilio, edad, sexo, apellido y nombres" (IFE, 1993, Op. Cit. p. 265).

En un gran esfuerzo realizado por el Registro Federal de Electores en poco más de un año, de 1990 a 1991, se tuvo listo el Padrón y la Lista Nominal que se utilizaría en las elecciones del año siguiente.

Además de los mecanismos de vigilancia y auditoría a la construcción del Padrón ya mencionados, en 1994 el Consejo General del IFE decidió crear el Consejo Técnico del Padrón Electoral "como instancia de colaboración y coadyuvancia ciudadana en los programas y actividades institucionales relacionadas con la integración del Padrón Electoral y los instru- 
mentos electorales a utilizarse en el proceso electoral" (Consejo General IFE, Sesión Ordinaria febrero 18 de 1994). De tal manera que el resultado de sus trabajos diera elementos al Consejo General para declarar válidos y definitivos el Padrón Electoral y las Listas Nominales de Electores que se utilizaron durante la jornada electoral del 21 de agosto de 1994.

Este Consejo Técnico del Padrón Electoral coordinó los trabajos de auditoría externa al Padrón Electoral y la Lista Nominal de Electores, que después de un primer ejercicio realizado por entidades externas al Registro Federal de Electores, llevaron a plantear la necesidad de realizar las Verificaciones Nacionales Muestrales (VNM), que desde los años 90 lleva a cabo el Registro Federal de Electores con la supervisión de la Comisión Nacional de Vigilancia, como acción de evaluación permanente de los instrumentos registrales y único en el mundo por sus dimensiones y continuidad a través del tiempo.

De 1994 a 2018, se han llevado a cabo 16 Verificaciones Nacionales Muestrales: 1994, 1996, 1997, 2000, 2002, 2003, 2005, 2006, 2008, 2009, 2011, 2012, 2014, 2015, 2017 y 2018 y se esperaría que se mantuvieran en el futuro.

A partir del año 2000, la Verificación Nacional Muestral se compone de dos encuestas: la de Cobertura y la de Actualización, las cuales generan información a partir de muestras independientes entre sí y permiten hacer inferencias estadísticas para estimar: i), el porcentaje de población empadronada y ii), la desactualizacion del instrumento registral a diversas escalas geográficas.

Los sucesivos análisis, basados en las Verificaciones Nacionales Muestrales, han generado resultados comparables a partir de 1996. El nivel de inferencia ha crecido: de 1996 a 2002 se obtuvieron indicadores a nivel nacional y de 2003 a 2018 se obtuvieron indicadores tanto a nivel nacional como estatal. Además, en algunas de la Verificaciones ha sido posible hacer inferencias por tipo de Sección (Urbana y No Urbana) y Distrito Electoral.

Estas encuestas han servido tanto para evaluar la calidad del Padrón y la Lista Nominal, como para conocer las necesidades de la ciudadanía que debe satisfacer el Registro Federal de Electores a través de la estimación de la demanda potencial que representan los nuevos electores que solicitaran su registro por primera vez y aquellos que pretendan en el futuro inmediato actualizar sus datos o renovar su credencial de elector.

Los indicadores que han generado sucesivamente las VNMs permiten tomar decisiones científicamente fundadas para garantizar mejoras en la calidad del Padrón. 


\section{LAS PROBLEMÁTICAS MÁS SIGNIFICATIVAS QUE INCIDEN SOBRE LA CALIDAD DEL PADRÓN}

En virtud de que la calidad del Padrón se manifiesta en sus dos componentes: su validez y confiabilidad, originados a su vez en dos situaciones objetivas asociadas a cada uno de estos componentes: su ausencia de sesgo y su precisión, respectivamente, las problemáticas más significativas que la afectan son: su nivel de cobertura y sus condiciones de actualización.

Los datos que se presentan a continuación provienen de los resultados de las Verificaciones Nacionales Muestrales y describen el panorama más reciente en la fecha de redacción de este texto (2018).

\section{Cobertura}

La universalidad en el nivel de cobertura del instrumento registral es una medida que garantiza la ausencia de sesgo, porque esto significa que no hay diferencias en el acceso al registro en el Padrón, generadas ya sea por las condiciones particulares de los individuos que limitan este registro, como puede ser el desconocimiento del ciudadano del derecho que tiene a registrarse, o porque la persona tiene condiciones físicas que le impiden o dificultan hacer el registro, ya sea porque su lengua limita su comunicación o es analfabeta y no puede entender los mensajes escritos que lo promocionan o también, porque la organización encargada del registro no ofrece las mismas facilidades para hacerlo a todas las personas y por lo tanto, cualquiera de estas situaciones dejarían sin oportunidad de empadronarse a las personas con discapacidades, a las personas que no saben leer o y escribir, a las que residen en localidades remotas o en donde no existen módulos de registro del RFE e incluso, a personas que no cuentan con la documentación necesaria para empadronarse, como puede ser una identificación personal o el acta de nacimiento y por lo tanto, el nivel de registro presentaría situaciones diferenciales asociados a las características de las personas, más allá de aquellas relacionadas con la propia voluntad de registrarse.

Todo lo mencionado en el párrafo anterior, significa que situaciones objetivas que tienen que ver con las personas o su entorno, introducen un sesgo en el instrumento registral, pero en el peor de los casos, pueden constituir una acción deliberada de la autoridad administrativa para dejar fuera del Padrón a determinados grupos de la población.

En resumen, la universalidad del Padrón, o acercarse cada vez más a esta cobertura universal, es una muestra de que están incluidas todas las personas que deben estar registradas y en caso de no lograrlo, esta des- 
viación debería poder explicarse como un hecho originado en la voluntad particular de los individuos de no querer registrarse, y no en condiciones estructurales que no son atendidas por el Estado, o por acciones del Registro Federal de Electores.

En el caso de México, los datos de las VNM muestran que el muy reducido porcentaje de las personas que aún no están empadronadas declaran que, o no tienen tiempo para hacerlo o no les interesa empadronarse.

Una primera situación que debe reconocerse asociada a la calidad del Padrón y que ha incidido positivamente en ella, es el avance tecnológico que hace posible el manejo de grandes volúmenes de información y que permite su almacenamiento, verificación y actualización prácticamente de forma instantánea, si se cuenta con el equipo y el personal para desarrollar esta tarea.

En el pasado, independientemente de las condiciones políticas que influyen en la calidad de los registros electorales, ${ }^{6}$ por más voluntad política que existiera para contar con un instrumento registral de buena calidad, la forma física en que se hacía el registro la condicionaba, porque era difícil comprobar, por ejemplo, la existencia de un registro duplicado. Este es un asunto que frecuentemente se ignora, pero que, como en otros muchos ámbitos de la vida en sociedad, está condicionado por la tecnología.

La cobertura universal en el Padrón de un país sería una realidad si al momento de nacer un individuo que tiene el carácter de nacional de ese país, es registrada, se captan características personales que lo van a identificar permanentemente como nombre, fecha y lugar de nacimiento, por ejemplo, y se le asigna una clave única que constituye su identificación y que va a estar permanentemente asociada con una serie de eventos que suceden a lo largo de su vida, como puede ser el ingreso a la escuela, la atención médica, el ingreso al trabajo, el matrimonio, o su fallecimiento, sólo para mencionar algunos de los eventos más relevantes. Si esta clave existe y es obligatorio su uso en los trámites que un individuo realiza en los diversos aspectos de su vida en sociedad, el archivo que contenga esta información sería una película a través de la cual se conocen las condiciones de las personas que la integran y que son relevantes para la propia sociedad. Esta, por cierto, es la intención de contar con una Cédula de Identidad Personal en los países en donde existe. Para el caso del Padrón, la persona automáticamente se incorporaría a éste cuando se cumplieran las condiciones que la norma establece, una de ellas sería llegar a la edad

\footnotetext{
${ }^{6}$ Por ejemplo, impulsar el empadronamiento en zonas en donde el voto le puede ser favorable a la autoridad política que desea asegurarse el triunfo en un proceso electoral y no atender total o parcialmente las necesidades de registro en otras zonas.
} 
en la que se adquiere la ciudadanía. Para las personas que adquieren la nacionalidad en otro momento de su vida que no es el nacimiento, también se asigna una clave de identificación personal en el momento en que se convierten en ciudadanos del país, asociada a este carácter, lo que les da derecho de ejercer el voto.

Lamentablemente, en México los esfuerzos por crear una Cédula de Identidad a través de la Cédula Única del Registro de Población (CURP), ${ }^{7}$ no han dado como resultado la creación de un registro universal de personas residentes en el país, tanto nacionales como extranjeros, a partir del cual se pudiera generar el registro electoral, ya sea de manera automática al obtener la ciudadanía al cumplir 18 años o cuando el ciudadano solicitara su registro con su clave de identificación. Sin embargo, aunque el registro fuera automático habría necesidad de actualizar los datos de la persona y por lo tanto, la acción de inscripción al Padrón no se eliminaría. En otros países que cuentan con clave de identificación personal, el registro electoral para participar en una elección debe hacerse en una fecha cercana previa a las elecciones para tener actualizado el lugar de residencia.

Sin que exista un registro de población del cual se derive el registro electoral y sin que éste sea obligatorio, la voluntad del ciudadano para formar parte del Padrón es el factor más significativo para explicar su nivel de cobertura, aunque no el único.

En la legislación, la inscripción al Padrón si bien se identifica como obligación ciudadana, es en realidad de carácter voluntario, por lo que aso-

${ }^{7}$ La Ley General de Población de 1974 establecía en su "Artículo 85.- La Secretaría de Gobernación tiene a su cargo el registro y la acreditación de la identidad de todas las personas residentes en el país y de los nacionales que residan en el extranjero. Artículo 86.- El Registro Nacional de Población tiene como finalidad registrar a cada una de las personas que integran la población del país, con los datos que permitan certificar y acreditar fehacientemente su identidad. Artículo 87.- En el Registro Nacional de Población se inscribirá:

I. A los mexicanos, mediante el Registro Nacional de Ciudadanos y el Registro de Menores de Edad; y

II. A los extranjeros, a través del Catálogo de los Extranjeros residentes en la República Mexicana.

Artículo 88.- El Registro Nacional de Ciudadanos se integra con la información certificada de los mexicanos mayores de 18 años, que soliciten su inscripción en los términos establecidos por esta ley y su reglamento. Esta ley establece la obligación de registrarse en el Artículo 90 de la Ley original de 1974 y en el Artículo 98 de la Ley actual, que a la letra dice: "Los ciudadanos mexicanos tienen la obligación de inscribirse en el Registro Nacional de Ciudadanos y obtener su Cédula de Identidad Ciudadana”.

Aunque la Ley General de Población de 1974 menciona ya el Registro de Población e Identificación Personal, es hasta el 20 de agosto de 1980, que se crea mediante el Decreto correspondiente el Registro Nacional de Población y hasta el 23 de octubre de 1996, que se emite el "Acuerdo para la Adopción y Uso por la Administración Pública Federal de la Clave Única de Registro de Población". Por la fecha en las cuales se emiten los decretos anteriores se hace evidente la importancia que se le ha concedido a este asunto. En gobiernos sucesivos, se ha propuesto como prioridad la creación de este instrumento con caráter universal sin que hasta la fecha de redacción de este texto se haya logrado. 
ciado al hecho de que se establezca en diversas disposiciones la obligatoriedad de votar sin que se ejercite sanción por no cumplir con esta obligación, hace que se carezca de normas para fomentar el registro en el Padrón.

En México, es cada vez más evidente que situaciones que van más allá de lo electoral y que motivan a los ciudadanos a registrarse, explican el incremento en la cobertura del Padrón. Una de ellas es la necesidad de contar con un documento de identificación personal confiable. Esta confiabilidad está fundada en dos conjuntos de características de la credencial de elector, relacionadas con: i), la manera en que se genera y se guarda la información del ciudadano para justificar su registro, es decir, el respaldo documental que el RFE mantiene digitalizado y ii), los candados de seguridad con los que cuenta, y que en forma evidente, son su fotografía y su(s) huella(s) dactilar(es), pero que son todo un conjunto que hacen de la credencial de elector un documento prácticamente imposible de falsificar. ${ }^{8}$ En todo caso, es más sencillo suplantar la identidad de una persona utilizando documentos ajenos de identificación personal previamente elaborados, como si fueran propios, que generar una credencial de elector falsa.

Los datos de la Verificación Nacional Muestral (VNM) 2018 permiten estimar una cobertura ligeramente superior a 98 por ciento, con lo que se está muy cerca de alcanzar la cobertura universal.

En la Tabla 1 se presentan las estimaciones de la evolución de la cobertura desde 1996, año a partir del cual las VNM son estrictamente comparables. La evolución de la cobertura es creciente en el periodo analizado con ligeras disminuciones que son estadísticamente significativas en años recientes. Puede verse en la Tabla 2, que, en el corte temporal más reciente, las mujeres presentan mayores porcentajes de empadronamiento en prácticamente todos los grupos de edad (la excepción la constituye el grupo de 80 o más años).

\footnotetext{
${ }^{8}$ Los elementos de seguridad que aparecen ya sea, en el anverso y reverso, o en ambos lados, de la credencial de elector, son: Tinta UV, en colores de tintas ultravioleta que son perceptibles con luz negra. Patrón debilitado, para fusionar el marco de la fotografía con el resto del diseño de la credencial. Diseños "Guilloche", con líneas difíciles de imitar con impresoras o fotocopiadoras, ya que al usarlas lo que se obtiene son imágenes a base de puntos y no de líneas. "Microtexto", que no es legible a simple vista, con el nombre del ciudadano o ciudadana a quien pertenece la credencial. Impresión "Arcoiris", que genera patrones de líneas con dos o más colores de tinta simultáneos. "Elemento Táctil", perceptible al tocarlo con las yemas de los dedos. "Fotografía Fantasma" con datos variables, creada por un programa que crea la imagen a partir de datos del ciudadano con un patrón variable. "Tinta OVI", que cambia de color según el ángulo de la luz con que se observe. "Diseño en Relieve" constituido por líneas con diseños especiales que simulan un efecto de relieve, difícil de reproducir con un escáner o con fotografías digitales. "Elemento Ópticamente Variable", con la leyenda "Instituto Nacional Electoral", la palabra "INE" y la urna con la boleta electoral entrando a la misma. Radiofrecuencia para confirmar su autenticidad en caso de que esto se requiera.
} 
Tabla 1: Evolución de la cobertura del padrón electoral. México, 1996-2018

\begin{tabular}{lc}
\hline Año & Cobertura \\
\hline 1996 & 88.7 \\
1997 & 90.8 \\
2000 & 93.4 \\
2002 & 93.6 \\
2003 & 94.2 \\
2005 & 95.0 \\
2006 & 95.4 \\
2008 & 96.1 \\
2009 & 95.2 \\
2011 & 97.5 \\
2012 & 97.6 \\
2014 & 98.2 \\
2015 & 97.7 \\
2017 & 97.1 \\
2018 & 98.3 \\
\hline
\end{tabular}

Fuente: Verificaciones Nacionales Muestrales. Instituto Nacional Electoral (INE). Registro Federal de Electores (RFE).

Aunque la cobertura supera ya 98 por ciento de la población en edad ciudadana, el empadronamiento diferencial por edad explica que no se alcance la universalidad y son los jóvenes menores de 20 años quienes presentan las cifras más bajas en la cobertura. Sólo el 88.7 por ciento de esta población está empadronada. El análisis del porcentaje de empadronados por edad y sexo muestra el incremento que se produce a partir de los 20 años que se resume en 98.3 por ciento en la población total.Incrementar la cobertura entre los jóvenes menores de 20 años constituye uno de los retos más importantes del Instituto Nacional Electoral. Si se puede incidir positivamente sobre el empadronamiento de este grupo de la población, alcanzar la cobertura universal se convierte en una posibilidad real en una sociedad democrática.

No se tiene información que permita identificar las causas por las cuales los ciudadanos más jóvenes no se empadronan. Hasta ahora, no se ha hecho una investigación que permita hacer inferencias en este sentido. Existen diversas investigaciones para conocer y explicar la participación política de los jóvenes en procesos electorales en México (Benítez Isidoro, 2012; 
Cuna Pérez, 2012; Aguilar López, 2017) las encuestas sobre la juventud que se han hecho en años recientes en México generan información en este sentido (Encuesta Nacional de Juventud 2011, IMJUVE, 2010; Encuesta Nacional de Valores en Juventud 2012, IMJUVE, 2012; Encuesta Nacional de Cultura Política de los Jóvenes en México 2012; IMJUVE, 2015); sin embargo, se ha dejado de lado preguntar a los jóvenes si están empadronados y tienen credencial de elector y, en caso de que no sea así, las razones por las cuales no se han empadronado. Generar esta información es una necesidad que debe atenderse en las encuestas que tengan como objetivo estudiar la participación política de los jóvenes.

Tabla 2: Porcentaje de empadronados por grupos de edad y sexo. México 2018

\begin{tabular}{lccc}
\hline Grupos de edad & Total & Hombres & Mujeres \\
\hline $18-19$ & 88.3 & 86.2 & 90.7 \\
$20-24$ & 96.6 & 98.3 & 99.0 \\
$25-29$ & 99.0 & 98.3 & 99.7 \\
$30-34$ & 98.7 & 98.6 & 98.7 \\
$35-39$ & 98.0 & 96.0 & 99.7 \\
$40-44$ & 99.0 & 98.8 & 99.2 \\
$45-49$ & 99.1 & 98.7 & 99.5 \\
$50-54$ & 98.7 & 97.9 & 99.4 \\
$55-59$ & 98.9 & 98.6 & 99.1 \\
$60-64$ & 99.5 & 99.2 & 99.7 \\
$65-69$ & 99.3 & 99.3 & 99.3 \\
$70-74$ & 99.4 & 98.9 & 99.8 \\
$75-79$ & 99.1 & 98.5 & 99.7 \\
80 y más & 98.9 & 99.2 & 98.7 \\
Total & 98.3 & 97.6 & 98.9 \\
\hline
\end{tabular}

Fuente: Verificación Nacional Muestral. Encuesta de Cobertura 2018. INE. RFE.

Por otra parte, en un estudio reciente Rivero (2018) ha tratado de relacionar el contexto social en el que se ubican los jóvenes con su empadronamiento diferencial, para encontrar posibles explicaciones a esta situación. Con este objetivo, relaciona algunos indicadores a nivel municipal como: participación electoral, carácter rural o urbano del municipio, acceso a módulos de inscripción al Padrón, y observa que los menores porcentajes de empadronamiento entre los jóvenes de 18 y 19 años de edad, se ubican en 
municipios rurales con baja participación electoral y en éstos, los trámites de inscripción se hacen en un municipio distinto al de residencia, por lo que recomienda implementar campañas de comunicación para fomentar el empadronamiento y la participación electoral. La autora sugiere, además, que la educación cívica desde los primeros años de educación escolarizada fomente el interés por participar en actividades electorales e inscribirse en el Padrón.

Aunque las cifras más recientes muestran que todavía existe una baja cobertura en el caso de los menores de 20 años, en relación con los grupos de mayor edad, los avances que se han logrado en este grupo son muy significativos a través del periodo cubierto con la información de las VNM.

Puede observarse en la Tabla 3 que entre los años 2000 y 2018, el porcentaje de empadronados en este grupo se ha incrementado en casi 20 por ciento. El interés de esta población por empadronarse y las acciones del Instituto Nacional Electoral por promover esta acción, a través de las campañas dirigidas a este sector han dado sin duda resultados, que se reflejan en estas cifras.

Tabla 3: Porcentaje de empadronados entre los jóvenes menores de 20 años. México, 2000-2018

\begin{tabular}{llccc}
\hline 2000 & 2005 & 2012 & 2015 & 2018 \\
\hline 69.0 & 71.4 & 77.1 & 79.2 & 88.3 \\
\hline
\end{tabular}

Fuente: Verificaciones nacionales muestrales. encuestas de cobertura, 2000, 2005, 2012, 2015 y 2018. INE, RFE.

Además de los resultados por grupos de edad ya comentados, el porcentaje total de empadronados o "cobertura del Padrón", según la información más reciente proveniente de la Verificación Nacional Muestral 2018, no muestra diferencias significativas por entidad federativa; tipo de Sección, según sea urbana o no urbana; tipo de Distrito, según sea éste de atracción, equilibrio o rechazo, de acuerdo con el carácter de los flujos migratorios, y se observan en todos los casos en las distintas unidades de observación porcentajes cercanos a 100 por ciento.

Puede decirse que los elevados niveles de empadronamiento son una indicación de la ausencia de sesgo que pudiera originarse en una acción deliberada o una limitación administrativa, que dejara fuera del instrumento registral a cierto sector de la población. 
Por lo tanto, además la cobertura del Padrón que se acerca a la universalidad, conviene observar la situación en la Lista Nominal para estimar las condiciones de este instrumento.

\section{La desactualización del Padrón y la Lista Nominal}

Una vez que un ciudadano se empadrona, debe obtener del Registro Federal de Electores su credencial de elector, esta acción le permitirá contar con un documento para poder votar. Aunque puede suponerse que quien acude a empadronarse tiene la obvia intención de contar con su credencial de elector, hay un porcentaje de personas que, por diversas razones, no acuden a recogerla a los módulos del RFE.

Según la información con la cual se declaró la validez del Padrón y la Lista Nominal para las elecciones federales de Julio de 2018, el número de registros en cada uno de los instrumentos registrales, fueron: 89'332,301 y $89^{\prime} 123,355$, respectivamente. Es decir, 99.8 por ciento de las personas empadronadas habían recogido su credencial de elector. 9

Ya que la Lista Nominal representa el universo de potenciales votantes, es importante prestar atención a las condiciones de este instrumento registral.

Como ya se mencionó previamente, existen una serie de situaciones de índole demográfica: migraciones y defunciones; organizacional: acceso a los lugares de registro y procedimientos documentales para hacerlo, promoción del registro, oportunidad para procesar los cambios en la situación de los registrados; e individual: notificación a la autoridad de cambios en el lugar de residencia y todas ellas se combinan para incidir sobre las condiciones de actualización del Padrón y la Lista Nominal.

Las Verificaciones Nacionales Muestrales realizadas por el Registro Federal de Electores para estimar las condiciones del Padrón y la Lista Nominal, constituyen un procedimiento de evaluación con bases científicas, que hacen evidentes las problemáticas más significativas en esta materia y que son, fundamentalmente, los cambios de domicilio sin notificar y las defunciones que no se dan de baja oportunamente, como se puede apreciar en la Tabla 4.

La Tabla 4 muestra los dos componentes de desactualización más importantes de la Lista Nominal, los cambios de domicilio que no se reportan y las defunciones que no se dan de baja. En esta tabla, no aparece un por-

${ }^{9}$ Diario Oficial de la Federación (DOF). ACUERDO del Consejo General del Instituto Nacional Electoral, por el que se declara que el Padrón Electoral y la Lista Nominal de Electores que serán utilizados en las Elecciones Federal y Locales del 1 de julio de 2018, son válidos y definitivos. $15 / 06 / 2018$. 
centaje de casos, de alrededor de tres por ciento que, en el trabajo de campo de las VNM, representan individuos en la Lista Nominal cuyos domicilios no fueron localizados y por lo tanto, no se pudo obtener información sobre ellos, o que si bien se localizó el domicilio, no fueron identificados por los vecinos y no fue posible establecer con precisión si se habían mudado, habían fallecido o se registró incorrectamente el domicilio en la credencial de elector. ${ }^{10}$

\section{Cambios de domicilio no reportados}

Cuando el ciudadano no reside en el domicilio que aparece en su credencial de elector, esta situación se puede presentar porque: i), haya mudado su residencia sin notificar al Registro Federal de Electores este cambio; ii), haya fallecido, o iii), porque deliberadamente el ciudadano cuando solicitó su credencial de elector haya aportado al Registro Federal de Electores información que no corresponde con su lugar de residencia, habiendo sido identificado este domicilio en la VNM.

Obsérvese en la Tabla 4, que los cambios de domicilio dentro del propio municipio representan el mayor componente de cambios de domicilio no reportados. Éstos han pasado de ser prácticamente uno de cada dos, en los primeros cortes transversales que se muestran en la tabla respectiva, a uno de cada tres casos en 2018. Se puede suponer que los ciudadanos no reportan este cambio ya que su credencial de elector puede seguir siendo utilizada en elecciones federales, estatales y municipales. También, en años recientes los cambios de domicilio en los que no se identifica el lugar de destino han crecido y, muy probablemente, esta situación es el resultado de la movilidad de personas que viven solas y sobre las cuales, al mudarse, no se puede conocer esta información. ${ }^{11}$

Por otra parte, la información que capta la Verificación Nacional Muestral refleja muy bien las condiciones de movilidad espacial de la población, ya que en el periodo que abarca la tabla, se hace evidente la disminución de la migración a otro país en años recientes, concretamente, la evolución del volumen de migrantes hacia Estados Unidos.

\footnotetext{
${ }^{10}$ En estos casos, por lo general, en áreas rurales la información cartográfica con que cuenta el RFE en la muestra de viviendas de la VNM es insuficiente y no permite ubicar el domicilio del ciudadano, mientras que en áreas urbanas, la movilidad de la población y la limitada interacción entre los vecinos hacen que las personas no se conozcan, especialmente cuando en el domicilio ha vivido una persona sola y las personas no pueden aportar información sobre esta persona.

${ }^{11} \mathrm{El}$ crecimiento de las viviendas en las que reside una sola persona se muestra claramente en las sucesivas VNMs y es una situación que se observa a nivel nacional, como lo hacen evidente otras fuentes de información ya sean los censos de población y otras encuestas. Así, un fenómeno demográfico como lo es el crecimiento de los hogares unipersonales, afecta la calidad de la información de estas fuentes.
} 
Calidad del Padrón Electoral y elecciones confiables / C. WELTI

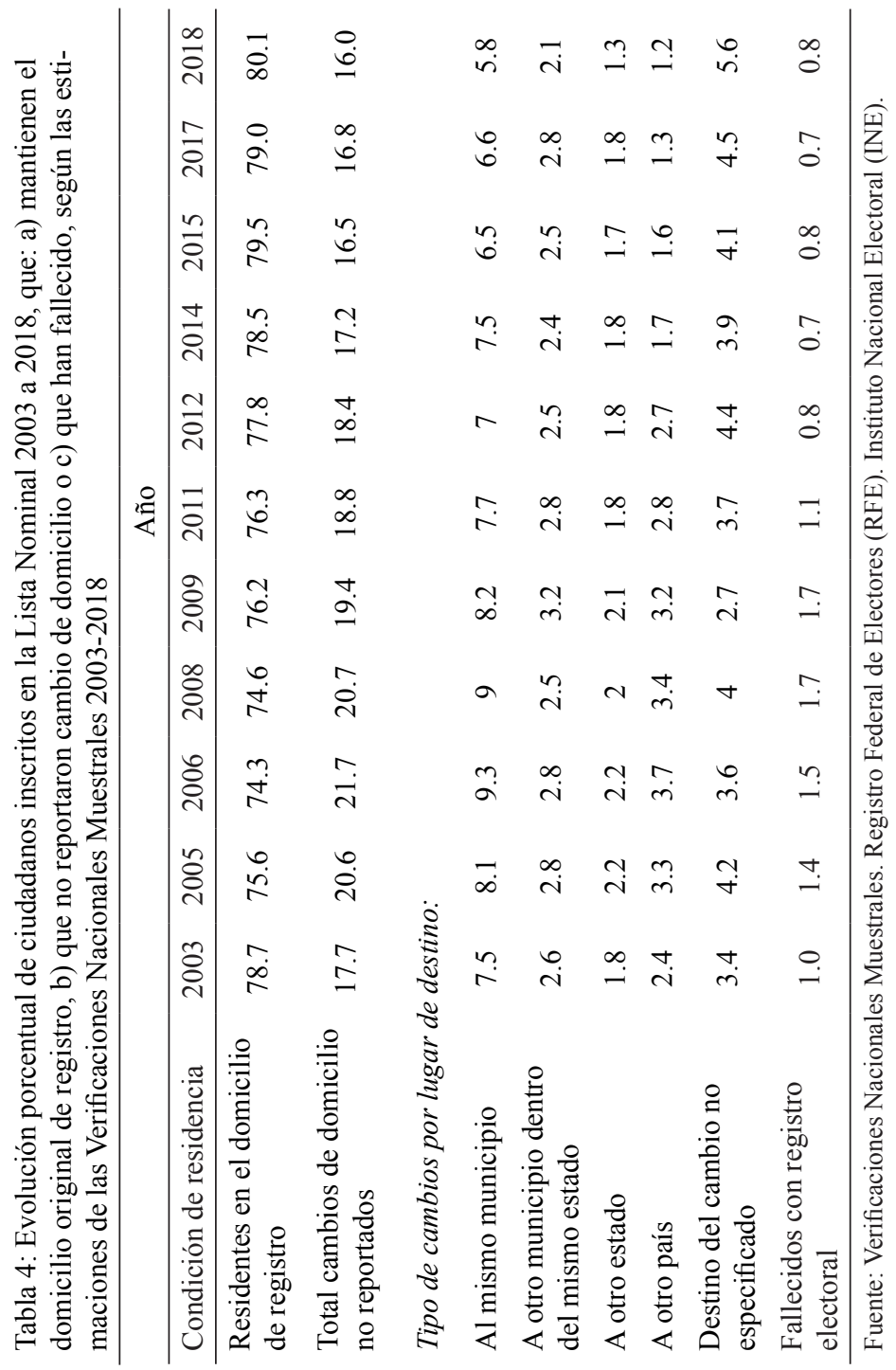




\section{Fallecidos en el instrumento registral}

En el imaginario social, durante mucho tiempo en México prevaleció la idea de que, "los muertos votaban" y sin tener evidencias de que esto realmente ocurría, esta idea se generaba simplemente por la constatación de que en la lista nominal que se usaba en una elección, seguían apareciendo personas que, especialmente en localidades rurales y con un reducido número de habitantes en donde mucha gente se conoce, se sabía que ya habían fallecido. No se puede suponer que la desaparición física de una persona trae como consecuencia su desaparición automática del Padrón y la Lista Nominal de Electores, porque para eliminar del Padrón y la Lista Nominal a una persona que ha fallecido, se debe certificar este hecho y cumplir con los procedimientos que la normatividad impone, lo que no siempre es posible por falta de información con la cual el Registro Federal de Electores fundamente esta acción.

Los niveles de desactualización del Padrón y la Lista Nominal producto de esta situación no fueron cuantificados con precisión en el pasado, hasta que se pudo contar con la información de la Verificación Nacional Muestral.

Es importante mencionar que evaluar la desactualización de un instrumento registral, sólo puede hacerse contrastando la información de cada individuo en el momento en que se registró por primera vez o cuando actualizó su registro, con las condiciones que presenta en la fecha de la evaluación.

La VNM de 1997, mostró un nivel de desactualización del Padrón por ciudadanos fallecidos no dados de baja, de 0.63 por ciento; ${ }^{12}$ en el año 2000, este porcentaje fue de 1.1; en 2003 de uno; en 2006 de 1.5, hasta alcanzar un máximo de 1.7 en los años 2008 y 2009, tendencia creciente que obligó a su atención con todas las herramientas con las que contaba el RFE para enfrentarla.

Las cifras mencionadas reflejan, un proceso demográfico en el cual el número de defunciones se incrementan año con año, producto del envejecimiento de la población y más recientemente, de la violencia en su expresión extrema que es el asesinato de más y más personas. Como puede verse en la Tabla 5, entre 1990 y 2017, el número de defunciones de personas adultas, más que se duplicó, al pasar de 317,408 a 658,494 y las muertes por homicidio de este mismo grupo de la población pasaron de 13 mil a 29 mil. Estos números muestran la magnitud de las operaciones que deben

12 Verificación Nacional Muestral al Padrón Electoral 1997. Documento Ejecutivo. Mayo de 1997. P.10. 
realizarse para identificar al individuo empadronado que fallece y darlo de baja del Padrón.

Tabla 5: Número anual de defunciones registradas de personas de 18 o más años de edad. México 1990-2017

\begin{tabular}{ll}
\hline 1990 & 317,408 \\
1995 & 356,820 \\
2000 & 378,781 \\
2005 & 443,220 \\
2010 & 543,129 \\
2015 & 597,869 \\
2017 & 658,494 \\
\hline
\end{tabular}

Fuente: INEGI. Estadísticas vitales.

La normatividad le otorga al Registro Civil un papel fundamental en la actualización del Padrón electoral, pero también a los partidos políticos y a los ciudadanos.

Sin pretender realizar un análisis histórico pormenorizado de la legislación al respecto, vale la pena mencionar las normas que prestan atención al tratamiento de los fallecidos, porque éste, ha sido un tema de la mayor significación para tener actualizado el Padrón.

El Decreto expedido por el presidente Ávila Camacho y publicado en el Diario Oficial de la Federación el 4 de enero de 1943, que reforma la Ley para Elecciones de Poderes Federales, en su Artículo 17 establece que:

Los jueces del Registro Civil remitirán a los Consejos Municipales correspondientes o a los de Distrito, ...en los primeros quince días del mes de abril del año en que deberán efectuarse las elecciones ordinarias, las listas de los electores muertos durante los 32 meses precedentes". ${ }^{13}$

La Ley Electoral Federal de 1951 publicada en el Diario Oficial 4 de diciembre de ese año en su Artículo 51 menciona que:

Los encargados del Registro Civil que autoricen las actas de fallecimiento o de matrimonio de menores de 21 años y mayores de $18, \ldots$ comunicarán estos hechos por escrito al Registro Nacional de Electores, suministrando los datos a su alcance para la identificación de la persona de que se trate.

${ }^{13}$ Decreto que Reforma Varios Artículos de la Ley para Elecciones de Poderes Federales. Diario Oficial de la Federación, 4 de enero de 1943. 
Debe recordarse al lector, que la referencia a las edades de 21 y 18 años, se origina en en hecho de que es hasta 1969 que se otorga la ciudadanía a los 18 años; antes, eran ciudadanas las personas que tuvieran entre 18 a 20 años y estuvieran casadas y las personas independientemente de su estado civil, sólo a partir de los 21 años. ${ }^{14}$

Es hasta la expedición de la Ley Electoral publicada el 5 de enero de 1973, que al quedar establecidas las facultades y obligaciones del Registro Nacional de Electores, en su Artículo 82, inciso II, se menciona que esta organización con el fin de "Mantener al corriente y perfeccionar el registro de electores en todo el país... podrá demandar la colaboración de los ciudadanos con fundamento en el artículo $5^{\circ}$ constitucional, en lo conducente, y acudir a todos los medios legales que le permitan preservar la fidelidad del padrón" y se identifica a los ciudadanos como coadyuvantes de mantener un Padrón actualizado.

En el Artículo 83 de esta Ley, no sólo se reitera la obligación de "los encargados del Registro Civil", de comunicar los hechos registrales de los que han dado fe al Registro Nacional de Electores, además, se establece que el plazo máximo para hacer esta notificación será de quince días después de la emisión del acta de defunción.

El Artículo 101, establece que: "los ciudadanos, y los partidos políticos nacionales pueden ocurrir a las delegaciones respectivas del Registro Nacional de Electores con las pruebas necesarias, solicitando la exclusión de personas en caso de incapacidad, inhabilitación o fallecimiento".

La Ley de Organizaciones Políticas y Procesos Electorales de diciembre de 1977, le dedica al Padrón Electoral, todo un capítulo relacionado con la depuración de este instrumento, e inicia con el Art. 134, estableciendo que: "El Registro Nacional de Electores deberá depurar de manera permanente el padrón electoral, suspendiendo este proceso exclusivamente del 11 de junio del año de la elección al día de ésta". Y se definen como "auxiliares del Registro Nacional de Electores en estas tareas, los ciudadanos, los partidos políticos y asociaciones políticas nacionales, de manera directa o a través de sus comisionados o representantes".

El Código Federal Electoral de 1987 publicado el 12 de febrero de ese año, establece en el Artículo 137, que:

Los funcionarios del Registro Civil están obligados, a darle aviso al Registro

Nacional de Electores, de los fallecimientos de personas mayores de dieciocho

${ }^{14}$ El 22 de diciembre de 1969, se publica en el Diario Oficial de la Federación la reforma constitucional al Art. 34 en que se establece que son ciudadanos mexicanos hombres y mujeres que "teniendo la calidad de mexicanos, reúnan, además, los siguientes requisitos: I. Haber cumplido 18 años y, II. Tener un modo honesto de vivir" (DOF, 22/12/1969. P. 2). 
años. Que registre (sic), dentro de los diez días siguientes a la fecha de expedición del acta respectiva, en los formularios que para el efecto les proporcione el Registro Nacional de Electores.

El Código Federal de Instituciones y Procesos Electorales de 1990, amplía las referencias a los actores responsables de mantener actualizado el Padrón Electoral en esta materia y el Artículo 92, inciso g) le asigna a la Dirección Ejecutiva del Registro Federal de Electores, la atribución de: "Establecer con las autoridades federales, estatales y municipales, la coordinación necesaria, a fin de obtener la información sobre fallecimientos de los ciudadanos...".

En el Artículo 162 inciso 2 queda establecido que "Los servidores públicos del Registro Civil deberán informar al Instituto de los fallecimientos de ciudadanos, dentro de los diez días siguientes a la fecha de expedición del acta respectiva". En el inciso 3 del mismo Artículo, se asigna a los jueces el deber de notificar al Instituto Federal Electoral "la declaración de ausencia o presunción de muerte de un ciudadano... dentro de los diez días siguientes a la fecha de la respectiva resolución". Una novedad la constituye el inciso 6 del mismo Artículo, en el que se determina que: "El Presidente del Consejo General del Instituto podrá celebrar convenios de cooperación tendientes a que la información a que se refiere este artículo se proporcione puntualmente".

El Código Federal de Instituciones y Procedimientos Electorales publicado en el Diario Oficial de la Federación el 14 de enero de 2008, que abrogó el Código Federal de Instituciones y Procesos Electorales de 1990, así como sus reformas y adiciones, dedica especial atención al Padrón Electoral en el Libro Cuarto, Título Primero en el que se hace referencia a los Procedimientos del Registro Federal de Electores.

En el Capítulo Tercero de este Código denominado, "De la actualización del catálogo general de electores y el padrón electoral", el Artículo 198, inciso 1, como lo había dejado establecido el Código anterior, determina que: "A fin de mantener permanentemente actualizado el catálogo general de electores y el padrón electoral, La Dirección Ejecutiva del Registro Federal de Electores recabará de los órganos de las administraciones públicas federal y estatal la información necesaria para registrar todo cambio que lo afecte". Además, el inciso 2 de este mismo Artículo, reitera que: "Los servidores públicos del Registro Civil deberán informar al Instituto de los fallecimientos de ciudadanos, dentro de los diez días siguientes a la fecha de expedición del acta respectiva". 
Especialmente importante es el párrafo 9 del artículo 199, en el que queda establecido que "Serán dados de baja del padrón electoral los ciudadanos que hayan fallecido, siempre y cuando quede acreditado con la documentación de las autoridades competentes, o en su defecto, mediante los procedimientos que determine la Comisión de Vigilancia”. Esta ultima frase define una acción de la mayor importancia para la actualización del Padrón y la Lista Nominal de Electores.

$\mathrm{Al}$ poner en práctica lo que menciona la norma precedente, en el mes de noviembre de 2008 la Comisión Nacional de Vigilancia aprobó el Procedimiento Alterno para dar de Baja del Padrón Electoral los Registros de Ciudadanos Fallecidos. Esta fue una decisión trascendental, porque en muchos casos de personas fallecidas, se tenía la certeza de su defunción, pero al RFE no había llegado la documentación que la certificara.

El Procedimiento inicia con un reporte ciudadano que puede ser efectuado por partidos políticos, por un reporte captado en IFETEL, en oficinas centrales o resultado de la aplicación de un operativo en campo llevado a cabo por el propio Registro Federal de Electores.

Su implementación incluye la captura de avisos ciudadanos y testimoniales, y el procesamiento de solicitudes que pueden hacer partidos políticos, funcionarios o ciudadanos, de aquellos casos que deben ser eliminados del Padrón por fallecimiento, al contar con elementos que prueben que una persona ha fallecido y que aún permanece en el Padrón y la Lista Nominal. Además, para dar a conocer al público la necesidad de dar de baja de estos instrumentos registrales a personas que han fallecido, el RFE realizó toda una campaña de difusión por diferentes medios, incluyendo el "perifoneo", ${ }^{15}$ para que los ciudadanos acudieran al RFE, a notificar el caso de fallecidos que no se hubieran dado de baja del Padrón y de los cuales tuvieran conocimiento.

Como es obvio suponer, el efecto de la mortalidad sobre la desactualización del Padrón es un proceso acumulativo que debe atenderse no sólo con las medidas descritas en párrafos anteriores, el establecimiento de un periodo de vigencia de la credencial de elector de corta duración, es decir, unos cuantos años, es quizá una de las acciones que mayor impacto tienen sobre la actualización del Padrón.

La Verificación Nacional Muestral de 2008 y la realizada el año 2009, hacen evidente el efecto del envejecimiento del Padrón sobre su desactualización, que se origina precisamente en las defunciones que no se han

${ }^{15}$ El perifoneo es la acción de emitir por medio de altoparlantes (bocinas) mensajes o avisos, que pueden ser informativos, publicitarios, o de alerta. 
dado de baja. En estas Verificaciones, se comparan las condiciones que en el instrumento registral presentan dos grupos de la población; uno, cuya credencial de elector se denominó "03", es decir, que el último recuadro para marcar su uso en elecciones federales tenía el número 03 y que todavía podían ser utilizadas en las elecciones del año 2009 y aquellas que tenían un periodo de mayor vigencia.

En la VNM 2008, se estimó que el 6 por ciento de los ciudadanos con credencial "03" en el Padrón habían fallecido, contra sólo 0.6 por ciento con credenciales emitidas con posterioridad, es decir la desactualización se multiplica diez veces al comparar estos dos grupos. En 2009, la relación es prácticamente la misma con porcentajes de siete y 0.6 , respectivamente.

Regresando a la Tabla 4, la baja significativa en el porcentaje de fallecidos que aún permanecían en la Lista Nominal que se presenta en esta tabla a partir del año 2011, es clara evidencia de las acciones implementadas por el RFE en esta materia y en las cuales, el Registro Civil notificando cada vez más de manera oportuna las defunciones, los partidos políticos a través de sus propuestas en la Comisión Nacional de Vigilancia y los ciudadanos, han participado.

La dimensión de las tareas de actualización para eliminar "a los muertos" en el Padrón la da el número de bajas que se producen cada año por esta razón y que se acercan cada vez más al número total de defunciones de ciudadanos mexicanos. En el quinquenio 2013-2017 en promedio se dieron de baja anualmente más de medio millón de registros. ${ }^{16}$

Sin embargo, aunque aumenten las bajas por defunción, puede pasar mucho tiempo entre la fecha de la defunción y la fecha de la baja en el Padrón, según la duración del proceso que incluye la generación del acta de defunción, la transmisión de esta información por parte del Registro Civil al RFE y la baja que éste realiza una vez que cuenta con esta información.

Precisamente, para hacer cada vez más eficiente la actualización del Padrón dando de baja las defunciones, disminuyendo el tiempo en que se da de baja un individuo después de que fallece e incrementando la proporción o porcentaje de bajas con relación al total de defunciones, el RFE ha establecido convenios de colaboración con el Registro Civil en todas las entidades federativas del país.

\footnotetext{
${ }^{16}$ En el año 2000, el número de bajas por defunción fue de 239,939; este número fue creciendo prácticamente año con año para llegar a un primer pico en el año 2009 de 462,925 bajas, crecimiento que probablemente refleje como se menciona en el texto, tanto la aplicación del "procedimiento alterno", como los esfuerzos que hizo el RFE en coordinación con el Registro Civil, para disminuir el rezago en las bajas por defunción. En el año 2017 el total de bajas por defunción fue de 559,020
} 
Además de la obligación que tiene el Registro Civil de transmitir oportunamente al RFE la información sobre las defunciones, los Convenios firmados con el Registro Civil de cada una de las entidades federativas del país, así como la aplicación del "Procedimiento alterno", para dar de baja oportunamente a las defunciones para las cuales se carece del Acta correspondiente, han impactado positivamente en la actualización del instrumento registral como los datos que se muestran a continuación lo hacen evidente.

Con la información disponible en el RFE, en cuyas bases de datos aparece cada uno de los casos que se dan de baja del Padrón, después de haber seguido los procedimientos establecidos por las normas, es posible estimar la magnitud de la diferencia entre la fecha de la defunción del ciudadano y la fecha de la baja en el Padrón, generando un indicador que se denominará sobrevivencia media en el Padrón.

La Tabla 6 muestra la evolución de la sobrevivencia media en el Padrón en cada una de las entidades federativas y la diferencia entre éstas. El panorama general es una disminución en la magnitud de este indicador, de tal manera que entre los años 2011 y 2017, a nivel nacional ha pasado de 10.5 a sólo 5.1 meses.

En el año 2011, en diez entidades pasaba más de un año (12 meses) para que se diera de baja una defunción y si bien esta situación ha desaparecido en el año 2017, hay entidades como Puebla en donde hay todavía un rezago significativo que debe atenderse. En el caso de esta entidad en el periodo analizado hay años en que la sobrevivencia media en el Padrón es consistentemente superior a un año. Es muy probable, incluso, que el rezago en Puebla en años recientes esté relacionado con el hecho de que por iniciativa del gobierno estatal se modificó en el año 2013 la Ley Orgánica Municipal y se quitó a las Juntas Auxiliares de los municipios la facultad de emitir actas sobre el estado civil de las personas centralizando estas tareas en la Secretaría General de Gobierno, lo que provocó serios conflictos, afectó las tareas del Registro Civil y un rezago en la emisión de actas. Esta reforma finalmente se derogó en el año 2016; sin embargo, parece que la problemática incidió sobre el flujo de información que desde esta entidad debió llegar oportunamente al RFE. 
Tabla 6: Sobrevivencia media en el padrón, en número de meses, de los ciudadanos dados de baja del padrón por defunción, según entidad federativa y año en que se produce la baja. México. 2011-2017

\begin{tabular}{|c|c|c|c|c|c|c|c|}
\hline \multirow[t]{2}{*}{ Entidad } & \multicolumn{7}{|c|}{ Años } \\
\hline & 2011 & 2012 & 2013 & 2014 & 2015 & 2016 & 2017 \\
\hline Aguascalientes & 7.9 & 4.1 & 2.7 & 2.0 & 3.7 & 2.4 & 2.0 \\
\hline Baja California & 10.1 & 4.5 & 4.7 & 4.1 & 5.0 & 3.8 & 3.3 \\
\hline Baja California Sur & 8.5 & 3.5 & 5.7 & 3.8 & 4.9 & 3.3 & 4.0 \\
\hline Campeche & 13.8 & 5.9 & 4.2 & 4.2 & 5.7 & 4.0 & 3.0 \\
\hline Coahuila & 19.7 & 18.1 & 8.4 & 8.5 & 7.2 & 3.8 & 4.2 \\
\hline Colima & 8.6 & 5.8 & 4.3 & 4.8 & 4.5 & 2.8 & 3.0 \\
\hline Chiapas & 9.2 & 5.1 & 4.4 & 2.7 & 4.2 & 2.9 & 3.8 \\
\hline Chihuahua & 9.6 & 5.8 & 18.5 & 6.2 & 4.1 & 3.0 & 1.9 \\
\hline Ciudad de México & 7.7 & 8.3 & 4.8 & 5.1 & 4.8 & 4.4 & 6.4 \\
\hline Durango & 15.8 & 14.8 & 9.8 & 17.0 & 10.6 & 7.1 & 7.0 \\
\hline Guanajuato & 11.6 & 5.2 & 8.4 & 13.0 & 12.7 & 7.4 & 3.7 \\
\hline Guerrero & 12.1 & 9.7 & 8.0 & 10.6 & 8.8 & 7.5 & 7.8 \\
\hline Hidalgo & 9.3 & 11.8 & 4.7 & 7.4 & 7.4 & 4.8 & 4.8 \\
\hline Jalisco & 10.3 & 8.6 & 10.4 & 8.8 & 8.4 & 10.8 & 9.2 \\
\hline Estado de México & 9.4 & 5.7 & 4.1 & 3.4 & 4.8 & 2.7 & 3.2 \\
\hline Michoacán & 12.0 & 6.9 & 6.7 & 5.0 & 6.1 & 6.1 & 3.9 \\
\hline Morelos & 8.7 & 8.7 & 3.5 & 3.8 & 4.8 & 4.6 & 6.5 \\
\hline Nayarit & 11.0 & 6.6 & 5.3 & 4.3 & 5.5 & 6.0 & 4.8 \\
\hline Nuevo León & 13.6 & 7.9 & 9.2 & 10.9 & 10.2 & 7.8 & 7.8 \\
\hline Oaxaca & 7.9 & 5.4 & 4.6 & 2.8 & 3.5 & 2.1 & 1.8 \\
\hline Puebla & 13.7 & 16.0 & 8.0 & 6.7 & 6.4 & 13.6 & 10.6 \\
\hline Querétaro & 9.1 & 4.9 & 3.5 & 3.2 & 4.5 & 3.4 & 2.8 \\
\hline Quintana Roo & 8.0 & 4.2 & 2.8 & 2.7 & 3.9 & 3.3 & 2.9 \\
\hline San Luis Potosí & 8.1 & 3.1 & 3.4 & 3.2 & 5.0 & 6.5 & 3.3 \\
\hline Sinaloa & 12.9 & 8.4 & 8.9 & 7.3 & 11.1 & 11.0 & 9.6 \\
\hline Sonora & 13.1 & 7.2 & 5.3 & 3.0 & 5.2 & 5.6 & 6.5 \\
\hline Tabasco & 9.7 & 4.1 & 4.5 & 4.4 & 6.5 & 7.3 & 7.3 \\
\hline Tamaulipas & 12.9 & 8.2 & 10.9 & 7.6 & 6.9 & 5.8 & 6.2 \\
\hline Tlaxcala & 8.1 & 4.3 & 1.9 & 1.4 & 3.5 & 2.0 & 1.8 \\
\hline Veracruz & 8.7 & 4.6 & 3.6 & 4.4 & 7.0 & 3.4 & 2.7 \\
\hline Yucatán & 8.6 & 3.7 & 6.7 & 7.9 & 4.8 & 2.9 & 2.3 \\
\hline Zacatecas & 8.3 & 4.2 & 3.6 & 2.6 & 4.2 & 2.4 & 2.0 \\
\hline Total nacional & 10.5 & 7.4 & 6.2 & 6.1 & 6.4 & 5.1 & 5.1 \\
\hline
\end{tabular}

Fuente: cálculos propios a partir de las bases de datos del Registro Federal de Electores. 
Es evidente que se ha logrado un avance sustantivo en dar de baja oportunamente a las defunciones de ciudadanos inscritos en el Padrón, ya que en el año más reciente para el cual se cuenta con información, no pasa más de medio año para que se ejecute esta baja y en diez entidades el periodo promedio (entre fecha de la defunción y fecha de la baja) es de menos de tres meses, algo insólito en la mayoría de los registros electorales en el mundo; sin embargo, aún queda por resolver el problema de no contar con información que permita dar de baja a un número significativo de fallecidos cuya identidad se desconoce, número que puede incrementarse ante el crecimiento de homicidios de personas que no es posible identificar. Este es un tema de la mayor importancia para garantizar la construcción de un Padrón Electoral confiable. ${ }^{17}$

A pesar de los esfuerzos por dar de baja a todos los ciudadanos que año con año fallecen, existe un número que no es posible dar de baja del Padrón y la Lista Nominal, porque como ya se mencionó, se carece de la información que lo posibilite $\mathrm{y}$, por tanto, las defunciones se van acumulando a lo largo del tiempo. Esto se ve reflejado en el hecho de que todavía exista 0.8 por ciento del total de registros en la Lista Nominal que corresponden a individuos ya fallecidos, cifra que se estima con los resultados de la Verificación Nacional Muestral más reciente y que equivalen a alrededor de 700 mil registros.

Como puede inferirse, ante la situación descrita, además de las acciones a las que se ha hecho referencia, la renovación de la credencial de elector por pérdida de vigencia es uno de los instrumentos más importantes para mantener la actualización de los instrumentos registrales, porque esto obliga a la población a actualizar sus datos cuando obtiene una nueva credencial.

En el año 2019, 7.8 millones de credenciales de elector pierden vigencia y los ciudadanos se ven obligados a renovarlas, con el incentivo de que la credencial como ya se mencionó, se convierte en un documento de identificación personal aceptado en todo tipo de trámites administrativos, por las llaves de seguridad con que cuenta.

\footnotetext{
17 Vale la pena mencionar que la información que contiene la credencial de elector para identificar con precisión a su poseedor ha permitido establecer la identidad de un número cada vez más significativo de personas victimas de homicidio, que habían sido reportadas como desaparecidas y cuyos cadáveres permanecían en calidad de desconocidos. En nota de Magali Juárez aparecida en el periódico El Financiero, el Consejero Presidente del INE, declaraba que hasta el mes de agosto de 2018, 5,316 personas desaparecidas habían sido identificadas a través de los datos multibiométricos del Padrón electoral. https://www.elfinanciero.com.mx/nacional/padron-del-ine-ayuda-a-identificar-cuerpos-de-desaparecidos-cordova.
} 


\section{Otras problemáticas que afectan la calidad de los registros electorales}

Además de las acciones descritas para actualizar y mantener un Padrón confiable, el Registro Federal de Electores implementa otras medidas con este objetivo, que incluyen la búsqueda de registros en los que exista la presunción de que son duplicados o tienen como referencia domicilios irregulares, o de aquellos en los que se puede presumir que la persona presentó documentación falsa para hacer el registro.

Para el tratamiento de cada una de estas problemáticas, existen protocolos que tienen como objetivo enfrentarlas desde su origen, de tal manera que se reduzca al mínimo la probabilidad de que un individuo se integre al instrumento registral de manera irregular, contraviniendo las normas que permiten a los ciudadanos empadronarse.

El lector interesado en conocer con detalle las acciones para atender los registros irregulares, puede consultar los documentos titulados: "Procedimiento para la detección y baja de registros duplicados", "Procedimiento para el Tratamiento de Registros con Datos de Domicilio Irregulares" y, "Procedimiento para la verificación de documentación presuntamente irregular", elaborados por el Registro Federal de Electores (RFE) y disponibles en el repositorio documental del Instituto Nacional Electoral. Estos documentos, si bien son elaborados por personal técnico especializado del propio RFE, incorporan los puntos de vista de los representantes de los partidos políticos expresados en la Comisión Nacional de Vigilancia; ahora bien, es importante mencionar algunos aspectos significativos de estos procedimientos que abonan a dar confiabilidad a los registros electorales.

Evitar duplicados es asegurarse de que cada persona aparece una sola vez en el Padrón. En la actualidad la tecnología de identificación biométrica disminuye prácticamente a cero la probabilidad de que una persona esté registrada más de una vez en el Padrón y este doble registro se evita en los propios módulos del INE en los que se expiden las credenciales de elector.

Sin embargo, en las revisiones que periódicamente se hacen a los instrumentos registrales y en especial, cuando éstos son sometidos a la revisión de los partidos políticos se hace un análisis de los casos que consideran duplicados para proceder a su tratamiento. Es común en las observaciones que hacen los partidos políticos a la Lista Nominal, que éstos detecten supuestos registros duplicados cuando existe coincidencia en los nombres, fecha de nacimiento o primeros dígitos de la clave de registro; cuando esto sucede el RFE procede a hacer un análisis de "duplas", hasta confirmar la situación de cada uno de los registros, primero en gabinete y si esto no es suficiente, se procede a su análisis en campo. Cuando se detecta un registro 
duplicado se procede a dar de baja el registro más reciente y se comunica esta baja a la persona con registro duplicado.

En una operación reciente de revisión de la Lista Nominal realizada en el año 2017 por los partidos políticos, éstos notificaron 303,941 casos como registros presuntamente duplicados, pero de la revisión exhaustiva de cada caso, sólo se encontraron 437 duplicados (436 en gabinete y 1 que tuvo que verificarse en campo), es decir en total 0.001 por ciento de los que se pensaba que fueran duplicados..$^{18}$

Se ha detectado que en estos casos la persona ha extraviado su credencial de elector, ha migrado a otro lugar e ignora que puede reponer su credencial y hace un nuevo trámite, ocultando deliberadamente que ya tenía una credencial de elector. Sólo excepcionalmente se han detectado casos de personas con dos credenciales emitidas con distintos nombres y que, en realidad, implican la suplantación de identidad y éstos son tratados como registros con documentación irregular.

La documentación irregular puede detectarse en el Módulo de Atención Ciudadana (MAC) y se pueden presentar dos situaciones: a), que habiendo sido expedida la credencial cumpliendo aparentemente con la normatividad, la documentación que respaldó el trámite haya sido alterada en alguno de los datos que contiene o b), que la documentación sea falsa desde su origen.

También es posible que en algún caso, una organización pública o privada, o un ciudadano en particular, informen al RFE que un registro se hizo con documentación irregular. En cualquiera de estos casos, el ciudadano que usó la documentación irregular debe aclarar la situación detectada.

Si del análisis que se deriva de los procedimientos establecidos normativamente, se concluye que la documentación es irregular, además de eliminar el registro del instrumento registral, el INE debe hacer una denuncia de hechos ante la autoridad ministerial, para que realice lo conducente.

En el caso de los domicilios irregulares, la estrategia para enfrentar esta problemática cuenta con herramientas cada vez más sofisticadas para detectar este tipo de registros y en especial, aquellos que en forma colectiva pretenden incidir sobre el resultado de una elección local a través de lo que se ha denominado "turismo electoral".

Las Verificaciones Nacionales Muestrales han detectado la existencia de ciudadanos que declaran como lugar de residencia un domicilio que no

\footnotetext{
${ }^{18}$ Informe que rinde la Dirección Ejecutiva del Registro Federal de Electores respecto del análisis realizado a las observaciones formuladas por los partidos políticos, en términos de lo previsto en los artículos 151 y 338 de la Ley General de Instituciones y Procedimientos Electorales. Dirección Ejecutiva del Registro Federal de Electores. INE. Abril de 2017.
} 
habitan y del análisis de cada uno de estos casos para explicar su origen, se identifican personas que han declarado como su domicilio, el domicilio de sus padres en el que desde hace varios años no residen, pero que, por carecer de un comprobante del domicilio que ocupan lo declaran como propio; o bien, se da el caso de personas que usaron como comprobante de domicilio el del lugar en que desempeñan su trabajo en un local en el que tienen un comercio o un taller de servicio del cual son propietarios y existen documentos a su nombre, sin que vivan allí.

Aunque en sentido estricto, estas situaciones no deberían presentarse, su existencia no afecta la confiabilidad del Padrón; sin embargo, la situación que compromete la confiabilidad del instrumento registral, se origina en el registro de un grupo de personas en cierta demarcación electoral sin que allí residan, con el propósito deliberado de incidir en una elección en el ámbito municipal.

Los ejemplos de esta acción se pueden documentar a través de diversas fuentes que van desde notas periodísticas a expedientes judiciales. Como referencia, porque tiene un carácter didáctico, el lector interesado puede leer el Expediente SCG/QDGAR/CG/27/2013, cuya resolución se encuentra en el documento identificado como INE/CG29/2018, disponible en el repositorio documental del Instituto Nacional Electoral y que trata el caso de una denuncia de "turismo electoral" de Valladolid, Yucatán a Cancún, Quintana Roo, que presentaron ante la autoridad electoral integrantes del grupo parlamentario del Partido Acción Nacional en el Senado de la República . A partir de los hechos denunciados, la autoridad electoral intervino, pero como puede observarse por la identificación numérica de los documentos que se mencionan, el proceso tardó cinco años en resolverse de 2013 a 2018 y efectivamente, se comprobó que se habían inscrito irregularmente un grupo de personas como residentes en Cancún, siendo residentes en Valladolid. Si la acción tuvo incidencia sobre el resultado de las elecciones, después de cinco años su reconocimiento es completamente extemporáneo, pero esto es responsabilididad de la autoridad judicial.

Para prevenir estas situaciones el RFE ha elaborado protocolos para el tratamiento de registros con domicilios irregulares de carácter preventivo y correctivo. En el caso de la prevención, se aplican programas de verificación de la identidad ciudadana o la identificación geo electoral del registro, detección de flujos inusuales de cambio de domicilio en el Módulo de Atención Ciudadana (MAC), detección de registros irregulares mediante análisis estadísticos y detección por denuncia de un tercero. 
Las acciones correctivas en esta materia se ven reflejadas en el número de bajas por domicilios irregulares que se realizan año con año y que son detectadas con el análisis estadístico de flujos de cambio de domicilio, operativos de campo y análisis de gabinete, que, por cierto, hacen evidente que en años electorales, los casos de registro con domicilios irregulares crecen significativamente, pero son detectados con oportunidad para disminuir o eliminar su incidencia sobre procesos electorales en los municipios del país.

En el Acuerdo publicado en el Diario Oficial de la Federación a través del cual, el Consejo General del Instituto Nacional Electoral, declara que el Padrón Electoral y la Lista Nominal de Electores que se utilizaron en las jornadas electorales del $1^{\circ}$ de julio de 2018 , son válidos y definitivos, se hace referencia puntual al proceso de depuración del Padrón en el caso de registros irregulares en los siguientes términos. "En el periodo comprendido entre el 08 de junio de 2015 al 30 de abril de 2018, la DERFE aplicó la baja del Padrón Electoral a 10,631 registros con datos personales irregulares o falsos, de los cuales, 703 fueron por documentación apócrifa, 1,344 por usurpación de identidad; así como 8,327 registros por domicilios irregulares". ${ }^{19}$ Como puede inferirse por su volumen, si no se hubieran detectado, su incidencia electoral a nivel nacional es prácticamente nula y reflejan más bien prácticas con otros propósitos distintos a los electorales; por ejemplo, contar con un documento de identificación que haga pasar a la persona que lo posee como ciudadana mexicana sin serlo, o cometer delitos y hacerse pasar por otra persona.

\section{Conclusiones}

En México, la construcción de un Padrón Electoral que asegure que en el aparecen las personas que tienen derecho a ejercer su voto en los procesos electorales y sólo las personas que tienen este derecho, ha sido una tarea de la mayor importancia para las organizaciones encargadas de administrar las elecciones. Con este objetivo desde hace ya varias décadas se han implementado acciones para contar con un Padrón con elevados estándares de calidad, lo que significa que es un instrumento confiable porque tiene precisión respecto a la población que incluye, que es representativa de la población de 18 años y más en el país, y que es válido, porque carece de sesgos que de manera intencional o no intencional, contribuyan a la sobrerepresentación o subrepresentación de algún grupo específico de la población.

\footnotetext{
${ }^{19}$ Diario Oficial de la Federación 15/06/2018.
} 
La calidad del Padrón es un proceso en el que participan diversos actores: ciudadanos, partidos políticos y funcionarios de diversas organizaciones como el Registro Civil, o el Poder Judicial y los encargados directamente de su administración en el Registro Federal de Electores, que interactúan en los espacios creados por los arreglos institucionales con este fin.

Precisamente, uno de los espacios organizacionales fundamentales para garantizar la calidad del Padrón es la Comisión Nacional de Vigilancia, en la cual los representantes de los partidos políticos ejercen esta tarea de vigilancia sobre el instrumento registral y presentan iniciativas para hacerlo confiable.

No hay duda de que la aplicación de la tecnología de punta en el manejo de la información y la identificación personal ha impactado positivamente la calidad del Padrón, al hacer posible implementar procesos de verificación de la información prácticamente de forma instantánea en el momento en el cual las personas se registran; no obstante, ha sido indispensable desarrollar procesos cada vez más sofisticados para evitar registros irregulares y en su caso, proceder a darlos de baja del Padrón. Cuando la prevención ha sido insuficiente, la depuración ha podido eliminar un número significativo de registros irregulares, antes de la fecha en que se celebran procesos electorales.

Debe resaltarse que en México, se ha establecido desde el año 1994, un mecanismo de evaluación de la calidad del Padrón y la Lista Nominal de Electores a través de la Verificación Nacional Muestral que, basada en una muestra probabilística diseñada con todo rigor científico, permite hacer inferencias sobre la cobertura y actualización de los instrumentos registrales.

La Verificación Nacional Muestral es una acción de evaluación única en el mundo por su carácter permanente, por el nivel de desagregación en el análisis que sus datos permiten y el diseño estadístico que, a su vez, ha sido sometido a evaluación, tanto en la Comisión Nacional de Vigilancia, como en el Comité Técnico de Evaluación del Padrón Electoral.

La cobertura del Padrón de electores está cerca de alcanzar la universalidad. La Verificación Nacional Muestral de 2018, permite estimar que 98.3 por ciento de la población de 18 años y más está empadronada; sin embargo, en los jóvenes de 18 y 19 años, la cobertura es todavía menor a 90 por ciento, por lo que habrá que diseñar y poner en práctica a acciones para incentivar su empadronamiento.

Aunque existe una desactualización de los instrumentos registrales, está tiene su origen fundamentalmente en la falta que cometen los ciudadanos 
al no reportar su cambio de domicilio, lo que no afecta la confiabilidad del Padrón. En todo caso, podría incidir en la participación electoral en procesos electorales, de carácter estatal o incluso nacional, porque la proporción más importante de estos cambios se produce en el propio municipio de residencia, lo que hace posible que los ciudadanos sin dificultad puedan emitir su voto en las jornadas electorales locales, ya que esta acción no debería involucrar un gran desplazamiento desde su lugar de residencia a la casilla electoral en la cual le corresponde votar en el propio municipio.

Otro componente de la desactualización, lo representan los fallecidos que no son dados de baja oportunamente; sin embargo, las bajas por defunción que año con año se producen en el Padrón, se acercan cada vez más al número total de defunciones y muestran el esfuerzo que la autoridad electoral, concretamente, que el Registro Federal de Electores realiza para obtener con oportunidad la notificación de defunciones de organizaciones como el Registro Civil, o de personas que comuniquen este tipo de eventos que, con la información que la normatividad impone, permitan proceder a dar de baja el registro de una persona fallecida.

Como se ha hecho evidente con la información disponible, el tiempo promedio para dar de baja del Padrón una defunción se ha reducido significativamente año con año y para 2017, este lapso es de sólo cinco meses entre la fecha de la defunción y la fecha de la baja. Esto, representa un gran avance en la actualización del instrumento registral, pero el incremento de los homicidios y la dificultad de identificar el cadáver de una persona asesinada en gran número de casos puede incidir negativamente en este proceso de actualización.

Registros con datos irregulares, incluyendo la declaración por parte de la persona que solicita su credencial de elector de un domicilio en el cual no reside, impacta la calidad del Padrón y por tanto su confiabilidad, no obstante, se han implementado medidas tanto preventivas como correctivas, que llevan a identificar oportunamente este tipo de casos para eliminarlos del Padrón.

Debe decirse que la construcción de un Padrón y una Lista Nominal de electores confiable ha sido tarea tanto de la autoridad que administra los procesos electorales, como de otro tipo de organizaciones como el Registro Civil o el Poder Judicial, los partidos políticos y los ciudadanos.

Finalmente, es claro que el instrumento registral es sólo uno de una serie de elementos que hacen de una elección un proceso confiable, pero sin éste, la expresión más elemental de la democracia como es el voto de los 
electores, no se podría ejercer con la garantía de que, quien tiene derecho al voto y sólo quien tiene este derecho puede hacerlo.

\section{REFERENCIAS BIBLIOGRÁFICAS}

Aguilar López, Jesús, 2017, El comportamiento electoral de los jóvenes en México. Trabajo preparado para su presentación en el $9^{\circ}$ Congreso Latinoamericano de Ciencia Política, organizado por la Asociación Latinoamericana de Ciencia Política (ALACIP). Montevideo, Uruguay, 26 al 28 de julio.

Baños Martínez, Marco Antonio y Palacios Mora, C., 2012, “El padrón electoral mexicano: análisis demográfico e innovaciones tecnológicas y seguridad de datos personales, 2011”, en Papeles de Población, vol. 18, núm. 71, marzo 2012. Pp. 121-141.

Benítez Isidoro, Miriam, 2012, Los determinantes de la participación electoral de los jóvenes en México. Tesis para obtener el título de Licenciada en Ciencia Política y Relaciones Internacionales. Centro de Investigación y Docencia Económica (CIDE).

Cuna Pérez, Enrique, 2012, “Apoyo a la democracia en jóvenes estudiantes de la ciudad de México. Estudio sobre el desencanto ciudadano juvenil con las instituciones de la democracia mexicana”, en POLIS 2012. vol. núm. 2, pp. 107-151.

Gómez Tagle, Silvia, 1990, Las Estadísticas Electorales de la Reforma Política. El Colegio de México.

IFE, 1993, Memorias del Proceso Electoral Federal de 1991. Tomo II, Vol. 2. Instituto Federal Electoral.

OES, 2014, Más elecciones observadas, mejores democracias, Memoria de Labores de 2014 del Departamento para la Cooperación y Observación Electoral (DECO) de la Secretaría de Asuntos Políticos. Organization of American States. Secretariat for Political Affairs. Department for Electoral Cooperation and Observation. OAS Official records; OEA/Ser.D/XX SG/SAP/III.34.

Ordorica, Manuel y Flores, René, 2003, Evolución del tamaño y estructura del padrón electoral. Comité Técnico del Padrón Electoral. Instituto Federal Electoral.

Rivero Fuentes, María Estela, 2018, Factores municipales asociados a la incorporación tardía de los jóvenes al Padrón Electoral. Comité Técnico de Evaluación del Padrón Electoral 2017-2018. Instituto Nacional Electoral.

Rosenberg, Jennifer S. and Chen, M., 2009, Expanding democracy: voter registration around the world. Brennan Center for Justice at New York University School of Law.

Yard, Michael (ed.), 2011, Civil and Voter Registries: Lessons Learned from Global Experiences. International Foundation for Electoral Systems (IFES). Washington. D. C.

Zúñiga González, Víctor, Borrego, Salvador y Ibarra, Vanessa, 2003, Evolución del Padrón Electoral 1989-2002. Comité Técnico del Padrón Electoral 2003. 


\section{RESUMEN CURRICULAR DEL AUTOR}

\section{Carlos Welti Chanes}

Es economista, sociólogo y demógrafo por la Universidad de Chicago. Es investigador titular del Instituto de Investigaciones Sociales de la Universidad Nacional Autónoma de México (UNAM). Es miembro del Sistema Nacional de Investigadores desde su fundación. Ha sido presidente de la Sociedad Mexicana de Demografía, coordinador general del Programa Latinoamericano de Actividades en Población y vicerrector de Investigación y Estudios de Posgrado de la Universidad Autónoma de Puebla. Es profesor de Análisis Cuantitativo del posgrado en la Facultad de Ciencias Políticas y Sociales de la UNAM. Es miembro del Consejo de Administración de la Asociación Mexicana de Planificación Familiar (MEXFAM) y preside su comité técnico. Ha publicado un gran número de trabajos sobre la fecundidad.

Dirección electrónica: welti@servidor.unam.mx 